\title{
A SPEA2 Based Planning Framework for Optimal Integration of Distributed Generations
}

\author{
Keshav Pokharel, Maizura Mokhtar, Joe Howe \\ Centre for Energy and Power Management \\ University of Central Lancashire, Preston, PR1 2HE, UK \\ Email:\{KPPokharel, MMokhtar, JMHowe\}@uclan.ac.uk
}

\begin{abstract}
The paper presents a multi-objective optimisation method for analysing the best mix of renewable and nonrenewable distributed generations (DG) in a distribution network. The method aims at minimising the total cost of the real power generation, line losses and $\mathrm{CO}_{2}$ emissions, and maximising the benefits from DG installations over a planning horizon of 20 years. The paper proposes new objective functions that take into account the longevity of DG operations as one of its selection criteria. The analysis utilises the Strength Pareto Evolutionary Algorithm 2 (SPEA2) for optimisation and MATPOWER for solving the optimal power flow problems.
\end{abstract}

\section{INTRODUCTION}

High levels of penetration of distributed generations (DG) are a new challenge for traditional electrical grids. There is no universally accepted definition for DG, however it is often used to depict small scale electricity generation of upto about 100 MW connected to low or medium voltage distribution network or nearer to the consumer side. DG in general refer, although not confined to, gas turbines, diesel generators, combined heat and power plants, wind turbines, solar photovoltaics and micro and small hydro power plants.

Although DG represent a small share of the electricity market, they play a key role for applications in which reliability is crucial: as a source of emergency capacity, and as an alternative to expansion of a local network. Despite these benefits, inadequate planning and inappropriate sizing and siting of the DG may lead to high power loss and poor voltage profile. This paper proposes a suitable planning and optimization technique to integrate both renewable and non-renewable DG in a distribution network with existing generation. The main target will be to find the optimal size and position of both renewable and non-renewable DG in the distribution network.

The framework utilises Strength Pareto Evolution Algorithm 2 (SPEA2). SPEA2, a type of multi-objectives evolutionary algorithm (MOEA), is chosen because of its suitability for optimizing the different types of stochastic and controllable DG simultaneously. SPEA2 is selected because it out-perform other MOEA techniques, e.g. the Non Sorting Genetic Algorithm II (NSGA-II) used to perform similar tasks [3], [4].

This paper is organized into five sections. Section II focuses on the DG planning process and the SPEA2 framework. Section III describes methodology and problem formulation. Section IV presents the test system and the discussion of results; and Section V concludes the paper.

\section{Multi-Objective DG Planning Process}

The DG planning goals are expressed in terms of objectives and constraints. Objectives target the maximization or minimisation of the network characteristics (attributes), while constraints specify the limits of the network based on the power balance rule and its boundaries. MATPOWER, an open source MATLAB power network simulation package developed by Zimmerman et al. (details in [5]), is used to conduct optimal power flow (OPF) that evaluate the attributes for the network being considered.

\section{A. Strength Pareto Evolutionary Algorithm 2 (SPEA2)}

SPEA2 is a highly regarded MOEA used to help solve a wide range of conflicting power system problems. SPEA2 performs its functionality based on evolutionary theory, that aims to find the most optimal (genetic) solution(s) through the improvement of genes and the survival of the fittest [6]. SPEA2 aims to produce final optimal solutions in the form of a Pareto-optimal front. The key steps in MOEA involve the presentation and coding of a system or the solution vector in order to describe the system to the MOEA, the formulation and evaluation of the fitness functions (Section III-B) that describe the characteristics of a system (represented by a solution vector), the application of the constraint functions (Section III-C) and genetic operators, i.e. reproduction, crossover and mutation iteratively, until the best Pareto-optimal solution is found.

\section{Methodology AND Problem Formulation}

A brief description of the methodology is presented in Fig. 3. Under this approach, the deterministic OPFs are performed in succession for each possible condition of the power network (DG production/demand) that is represented by a solution vector. The network variables resulting from the OPF (voltage, power flows) permit the calculation of other electrical attributes (e.g. line losses, existing generations), environmental attributes (e.g. load $\mathrm{CO}_{2}$ factor), and economic attributes (e.g. DG benefits, total cost). The process is repeated for a number of times (generations) until a convergence condition based on a required degree of precision is achieved.

SPEA2 is used to optimise the placement and size of the DG using the following three key steps of MOEA. 


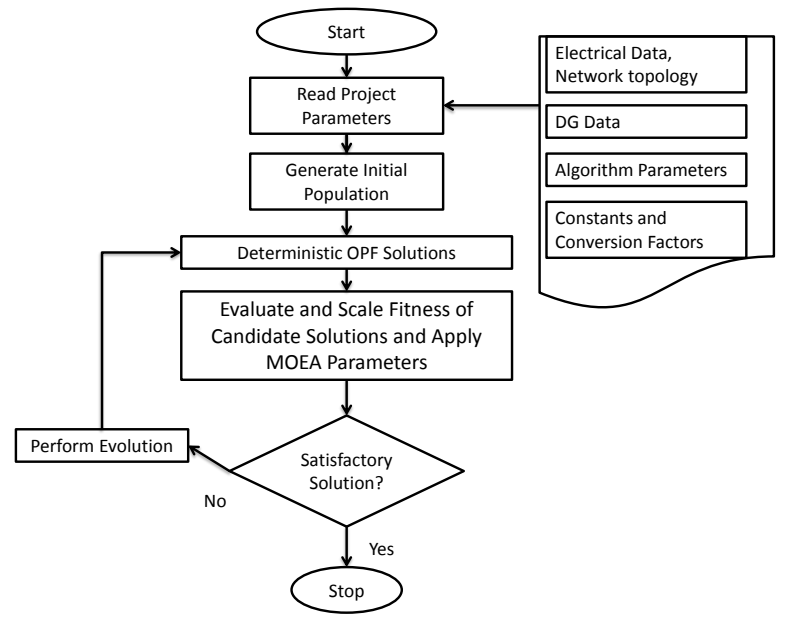

Fig. 1. Implementation of the Optimisation Algorithm

\section{A. Coding of the Solution Vector}

The solution vector codes the four control variables for each of the DG options integrated in the distribution network. The control variables used are $x, z, p$ and $v$, each representing the location, size, node power and node voltage of a DG option. Real number coding is used for all the four control variables so that each solution vector consist of a string of real numbers corresponding to the number of DG candidates.

\section{B. Fitness Objectives Formalization and Evaluation}

The objectives considered are: (1) the minimisation of real power generation costs, (2) the minimisation of system losses, (3) the minimisation carbon emissions, and (4) the maximisation of the total annual benefits from DG. The multiobjectives are formulated as:

$$
\begin{gathered}
f(c)=\sum_{g=1}^{n_{g}} \text { LCOE }_{g} \mathbf{x} E_{g} \\
f(p)=\sum_{l=1}^{n_{l}} \text { Linelosses }_{l} \mathbf{x} C_{E} \mathbf{x} 8760 \\
f(e)=\sum_{g=1}^{n_{g}} \text { Environmental Attribute }_{g} \\
f(b)=\sum_{g=1}^{n_{g}} \text { DG Benefits } \text { Bi }_{g} \\
E_{g}=I_{g} \mathbf{x} C_{g} \mathbf{x} 8760
\end{gathered}
$$

$n_{g}$ and $n_{l}$ are the number of DG options and branches respectively. $L C O E_{g}$ and $E_{g}$ are the levelised cost of real power generation and the annual energy output from a DG. $I C_{g}$ and $C F_{g}$ are the installed capacity and capacity factor of a DG. $C_{E}$ is the average electricity tariff considered for the analysis $(0.05 £ / \mathrm{kWh})$.
1) Economic Attributes: The Minimisation of Real Power Generation: The economic attributes consider the time value of money. The Levelised Cost of Energy ( $L C O E)$ is the most transparent term used to measure electric power generation costs, and is widely used as a tool to compare the generation costs from differing sources. It is a measure of the marginal cost (the cost of producing one extra unit) of electricity, over a defined period. The minimisation of the $L C O E$ favours the solutions with the least overall spending considering the entire lifetime of the DG.

In this paper, two attributes have been mainly considered for the economic analysis: $L C O E$ of the $\mathrm{DG}(£ / \mathrm{kWh})$ and annualised DG benefits ( $£$ /year). One of the most common methods used to translate these attributes into common comparable values, is to convert all the costs and benefits into annuities (i.e. equal annual values) considering the time value of money. The costs of DG are levelised costs of generation ( $L C O E$ ) in $£ / \mathrm{kWh}$ considering both the fixed installation cost at the beginning of the evaluation period (year zero) and the variable costs occurring annually throughout the planning horizon. Although the $\mathrm{O} \& \mathrm{M}$ costs vary from year to year in practice, they have been considered constant through the planning period for simplicity.

2) Line Losses: Active line losses depend on the magnitude of the current and the resistance. Line losses is calculated as:

$$
\text { Linelosses }_{l}=3\left|I_{\text {line }}\right|^{2} R
$$

Where $\left|I_{\text {line }}\right|$ is the magnitude of line current and $R$ is the line resistance. Summation of line losses for all the branches gives the total line losses.

3) Environmental Attribute: The environmental attribute is measured in terms of the $\mathrm{CO}_{2}$ emission. This is coined as the concept of load $\mathrm{CO}_{2}$ or $\mathrm{LCO}_{2}$ factor as indicated in [7]. Load $\mathrm{CO}_{2}$ factor indicates the $\mathrm{CO}_{2}$ emission resulting from energy usage (and generation) of the DG and is expressed in grams of $\mathrm{CO}_{2}$ per $\mathrm{kWh}\left(\mathrm{g}-\mathrm{CO}_{2} / \mathrm{kWh}\right)$.

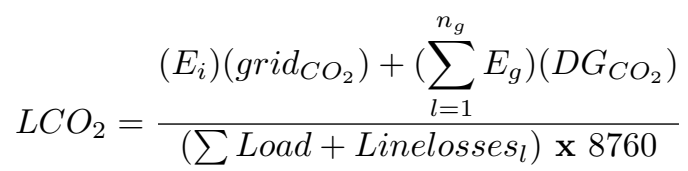

$L C \mathrm{O}_{2}$ depends on the total energy imported from the grid (or energy generation from existing generators in the network), $E_{i}$ and the DG output, $E_{g} \cdot g_{r i d} \mathrm{CO}_{2}$ and $D G_{\mathrm{CO}_{2}}$ are the average $\mathrm{CO}_{2}$ emission values of the grid (currently set at $539 \mathrm{~g}-\mathrm{CO}_{2} / \mathrm{kWh}$ [8]) and the DG respectively. $D G_{\mathrm{CO}_{2}}$ is the ratio of the total $\mathrm{CO}_{2}$ emission of DG over the total energy generated and dispatched.

4) The benefits of DG: The evaluation of DG benefits consists of the assessment of the benefits and costs over a period of one year. Net benefits are calculated by deducting the annual levelised costs from the annual revenues that are obtained from the DG installations. Two sources of revenue considered are: (1) from the direct sale of energy and (2) through the incentives received from producing the renewable 
energy including CHP (e.g. feed-in-tariff, FIT). The FIT is a scheme that pays for the "green" electricity. The main benefit of FIT is the generation tariff, which is paid for every $\mathrm{kWh}$ of electricity produced. The total benefit from the DG is calculated as:

$$
D G_{\text {benefits }}=\sum_{i=1}^{n_{g}} C_{E} E_{g}+\sum_{i=1}^{n_{d}} F I T_{d} D G_{d}-f(c)
$$

$F I T_{d}$ and $D G_{d}$ are the governments green benefits for a renewable DG (including CHP) entitled for the benefit and the annual energy output from that DG respectively (indexed by the letter $d$ ).

\section{Constraint Functions}

The constraint functions specify the boundaries of the network and attributes being considered. The evolution towards the most optimal Pareto front is achieved by validating the evolved solutions at each generation with the constraints equations (9)-(14).

$$
\begin{gathered}
\theta_{b(\min )} \leq \theta_{b} \leq \theta_{b(\max )}, b=1, \ldots, n_{b} \\
V_{b(\min )} \leq V_{b} \leq V_{b(\max )}, b=1, \ldots, n_{b} \\
P_{g(\min )} \leq P_{g} \leq P_{g(\max )}, g=1, \ldots, n_{g} \\
Q_{g(\min )} \leq Q_{g} \leq Q_{g(\max )}, g=1, \ldots, n_{g} \\
S_{l(\min )} \leq S_{l} \leq S_{l(\max )}, l=1, \ldots, n_{l} \\
n_{g}<n_{g(\max )}, g=1, \ldots, n_{g}
\end{gathered}
$$

$\theta$ and $V$ refer to the voltage angle and magnitude. $P, Q$ and $S$ refer to the real and reactive powers and the branch thermal limits. The indexes $b, g, l, \max$ and $\min$ represent the node (bus), DG type, line (branch), maximum value and minimum value respectively.

Distributed generators usually provide energy with a unitary power factor. The analysis has been conducted considering the cost of real power generation. However, the reactive power constraints in the problem formulation (12) make sure that the reactive power of each generation is obeyed in order to maintain acceptable voltage limits and the uniform power factor. Reactive power flows can give rise to substantial voltage changes across the system, hence its necessary to maintain reactive power generation from the generators within their specified limits $\left(Q_{g-\min }\right.$ and $\left.Q_{g-\max }\right)$.

\section{Test System}

The network being considered is the IEEE 14 bus network [9], the block diagram of which is shown in Fig. 2. MATPOWER is used to validate each possible generation condition of the network represented by a chromosome and perform OPF to calculate the electrical variables (e.g. voltages, line losses). These variables will be used to calculate other planning attributes like technical, economic and environmental attributes which in turn will be fed to the SPEA2 to evaluate the fitness values. The IEEE 14 bus network is modified to facilitate the MATPOWER OPF validation of each generating option with more number of DG. The modifications made are: (1) the increase of the cost parameters of existing generators by 10 , (2) the setting of the maximum power generation capacity $P_{g}$ (max.) of generators at node $1,3,6$ and 8 to be equal to their $P_{g}$ respectively; and (3) the setting $P_{g}$ (max.) of generator at node 2 to be $41 \mathrm{MW}$ instead of of $40 \mathrm{MW}$. The voltage constraint in the network is deterministic and is limited to $+/-6 \%$ of the nominal voltage (1 pu).

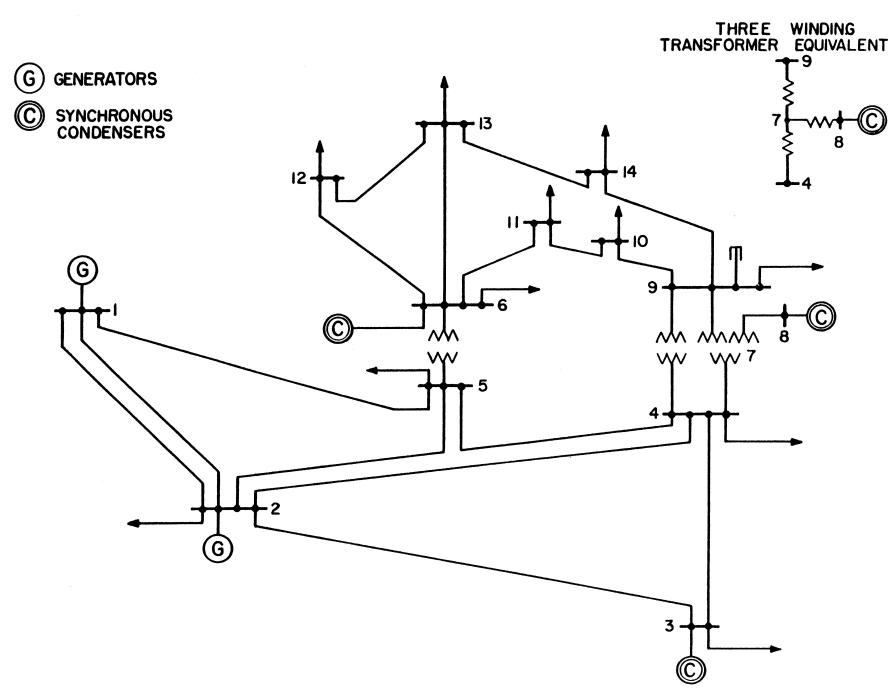

Fig. 2. IEEE 14 Bus Test Network [9]

A brief description of the methodology is presented in Fig. 3. Under this approach, the deterministic OPF are performed in succession for each possible condition of the power network (DG production/demand) that is represented by a solution vector. The network variables resulting from the OPF (voltage, power flows) permit the calculation of other electrical attributes (e.g. line losses, existing generations), environmental attributes (e.g. load $\mathrm{CO}_{2}$ factor), and economic attributes (e.g. DG benefits, total cost). The process is repeated for a number of times (generations) until a convergence condition based on a required degree of precision is achieved.

\section{E. DG Data}

Five different types of DG are considered for analysis: diesel generator, gas turbine (GT), combined heat and power plant $(\mathrm{CPH})$, solar photovoltaics (SPV) and wind turbine (WT). The 


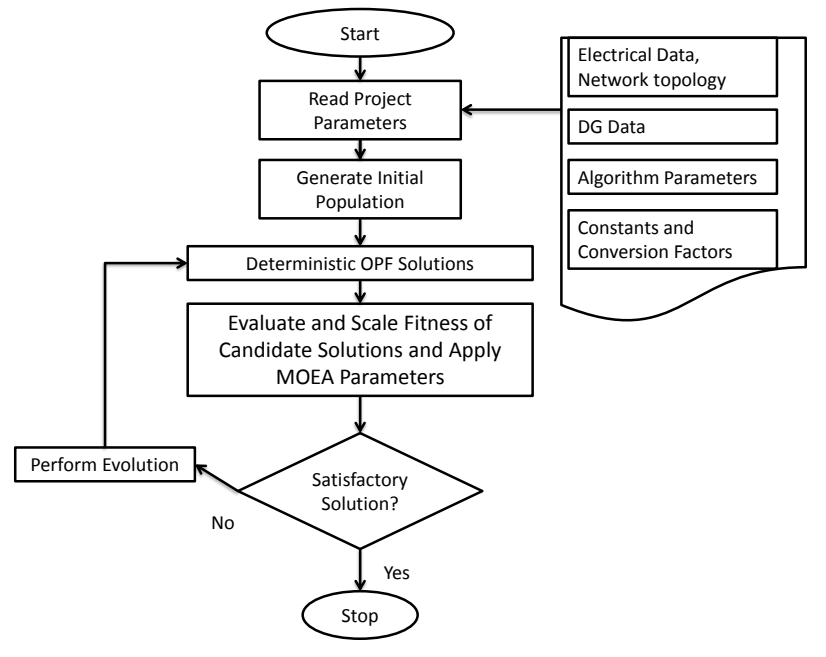

Fig. 3. Implementation of the Optimisation Algorithm

technical parameters, constants and conversion factors of these generators are listed in Table I. The financial parameters and LCOE calculations are presented in Table II.

\section{Results And Discussions}

The SPEA2 parameters used for the analysis are:

- Population and archive sizes $=250$.

- Number of generations $=400$.

- Crossover rate and type $=0.85$, Uniform.

- Mutation rate $=1 / 70(0.01423)$.

Fig. 4 (a), (b) and (c) show plots of the different objectives for the optimal solutions obtained after 400 generations. For illustration, three solutions (A: solution with lowest cost of $P_{g}$, B: solution with lowest $\mathrm{LCO}_{2}$ and C: solution with lowest total line losses) from the Pareto-fronts are chosen to facilitate the description of front for further discussion. The solutions shown in Fig. 4 produce conflicting scenarios between the objective functions. If all the objectives are equally important, none of these solutions is the best with respect to all the objectives. However, these sets of solutions can help the system planner to evaluate the solutions considering their required criteria.

Table III present some of the characteristics of the optimal solutions $\mathrm{A}, \mathrm{B}$ and $\mathrm{C}$, where the DG penetration levels are expressed in terms of ratio of annual DG energy production to the annual load (in energy term).

Among the three cases, the total DG cost is the highest for Case C. However the lowest line losses and generation of more energy result in the decrease in the average cost of energy per unit $(£ / \mathrm{kWh})$.

It is seen that with given cost structures and technical parameters, gas turbines and CHP with higher capacity factors and lower generation costs (Table II) are normally the attractive options for energy generation (Table III). Consequently, solutions that are non-dominated in the objectives of lower $\mathrm{CO}_{2}$ emission (Case B) and lower line losses (Case C) also

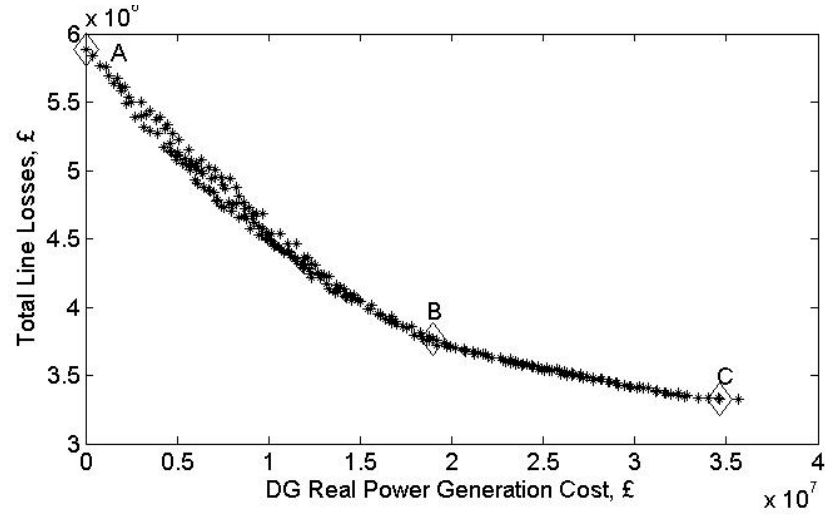

(a) Total Line Losses Vs DG Real Power Generation Cost: Tota line losses decreases linearly with increase in the DG costs. This is because more DG are selected nearer to the loads.

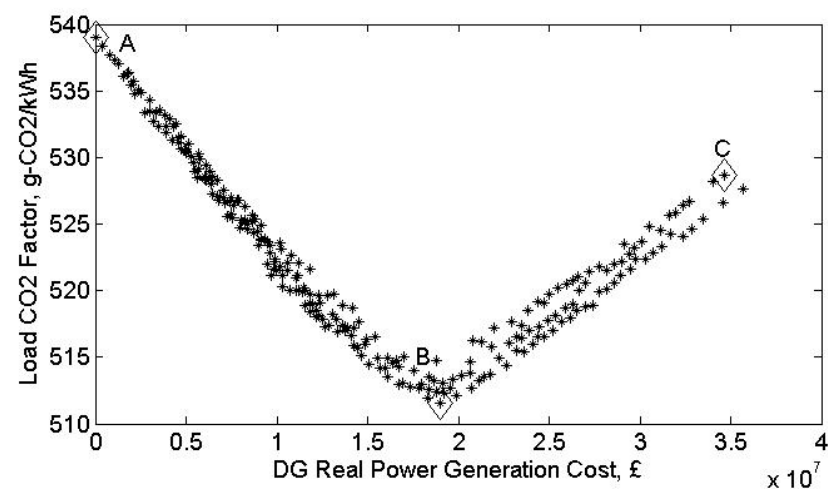

(b) Total Line Losses Vs DG Real Power Generation Cost: Selection of higher number of DG (except diesel generators) decreases the load emission factor from A to B. However, higher number of diesel generators (with high emission factor) causes the load emission factor to increase from $\mathrm{B}$ to $\mathrm{C}$.

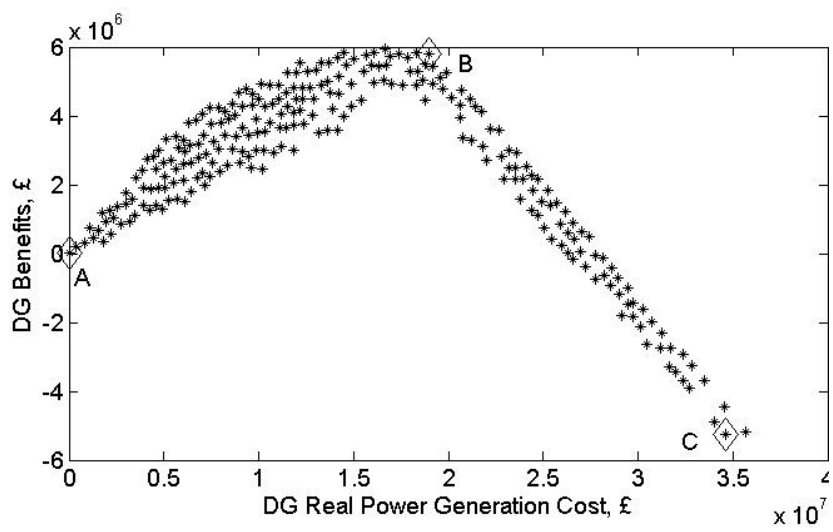

(c) DG Benefits Vs DG Real Power Generation Cost: Similar to Fig. (b) above, selection of higher numbers of DG (except diesel generators) increases the total benefit from A to B while the higher number of expensive diesel generators causes the total benefits to decrease from $\mathrm{B}$ to $\mathrm{C}$.

Fig. 4. Plots of Optimal Solutions 
TABLE I

DG DATA

\begin{tabular}{|l|r|l|l|l|l|l|l|l|}
\hline Type & $\mathrm{P}_{g}(\mathrm{MW})$ & $\begin{array}{l}\mathrm{P}_{g} \text { (Max.) } \\
(\mathrm{MW})\end{array}$ & $\begin{array}{l}\mathrm{P}_{g} \text { (Min.) } \\
(\mathrm{MW})\end{array}$ & $\begin{array}{l}\mathrm{Q}_{g} \text { (Max.) } \\
(\mathrm{MVAr})\end{array}$ & $\begin{array}{l}\mathrm{Q}_{g} \text { (Min.) } \\
(\mathrm{MVAr})\end{array}$ & $\begin{array}{l}\text { Capacity Fac- } \\
\text { tors }\end{array}$ & $\begin{array}{l}\text { Environmental } \\
\text { Emission Factors } \\
\left(\mathrm{kg}-\mathrm{CO}_{2} / \mathrm{kWh}\right)\end{array}$ & $\begin{array}{l}\text { FIT } \\
(f / \mathrm{kWh}) \\
{[14]}\end{array}$ \\
\hline Diesel & 0.06 & 0.06 & 0 & 0.06 & -0.06 & 0.9 & $0.88[12]$ & - \\
\hline Gas & 0.055 & 0.055 & 0 & 0.055 & -0.055 & 0.9 & $0.326[8]$ & - \\
\hline CHP & 0.054 & 0.025 & 0 & 0.025 & -0.025 & $0.6375[10]$ & $0.29[13]$ & - \\
\hline SPV & 0.05 & 0.05 & 0 & 0.05 & -0.05 & $0.1151[11]$ & $0.045[12]$ & 0.329 \\
\hline WT & 0.05 & 0.05 & 0 & 0.05 & -0.05 & $0.2712[11]$ & $0.011[12]]$ & 0.253 \\
\hline
\end{tabular}

TABLE II

LCOE CALCULATIONS

\begin{tabular}{|c|c|c|c|c|c|}
\hline & Diesel & GT & $\mathrm{CHP}^{a}$ & SPV & WT \\
\hline Rated Power $(\mathrm{kW}), \mathrm{A}$ & 60 & 55 & 54 & 50 & 50 \\
\hline Capacity Factor, B & 0.9 & 0.9 & 0.6375 & 0.11 & 0.27 \\
\hline Installation Cost $(£ / \mathrm{kW}), \mathrm{C}$ & $864^{b}$ & $866^{b}$ & - & $3339[21]$ & $3762[21]$ \\
\hline Total Installation Cost $(£), \mathrm{D}=\mathrm{AxC}$ & 51840 & 47630 & $65700[20]$ & 166950 & 188100 \\
\hline Heat to Power Ratio, E & - & - & $1.8[20]$ & - & - \\
\hline Installation Cost attributed to Electricity $(£), \mathrm{F}=\mathrm{D} /(\mathrm{E}+1)$ & 51840 & 47630 & 23464 & 166950 & 188100 \\
\hline Electrical Energy (kWh/yr), G=8760xAxB & 473040 & 433620 & 301563 & 48180 & 118260 \\
\hline Annuity Factor, $\mathrm{H}^{c}$ & 10.59 & 10.59 & 10.59 & 10.59 & 10.59 \\
\hline Annuity of Installation Cost, I = F/H & 4893.33 & 4495.94 & 2214.86 & 15758.9 & 17755.31 \\
\hline Maintenance Cost ( $£ /$ year $), \mathrm{J}$ & $1060^{d}$ & $971.67^{d}$ & $4250[20]$ & $1240[21]$ & $2070[21]$ \\
\hline Maintenance Cost attributed to Electricity ( $£ /$ year), $\mathrm{K}=\mathrm{J} /(\mathrm{E}+1)$ & 1060 & 971.67 & 1517.86 & 1240 & 2070 \\
\hline O\&M (Fuel) Cost $(£ / k W h), \mathrm{L}$ & $0.14[22]$ & $0.027[23]$ & $0.027[23]$ & 0 & 0 \\
\hline O\&M (Fuel) Cost ( $£ /$ year), $\mathrm{M}=\mathrm{GxL}$ & 63860.4 & 11707.74 & 8142.2 & 0 & 0 \\
\hline Total Annual Cost $(£), \mathrm{N}=\mathrm{I}+\mathrm{K}+\mathrm{M}$ & 69813.73 & 17175.34 & 11874.92 & 16998.9 & 19825.31 \\
\hline LCOE $(£ / \mathrm{kWh}), \mathrm{O}=\mathrm{N} / \mathrm{G}$ & 0.1476 & 0.0396 & 0.0394 & 0.3528 & 0.1676 \\
\hline
\end{tabular}

${ }^{a}$ The assessment of costs for CHP is not straight forward as with other DG units as CHP normally provide electricity mainly as a by-product of heat generation. The heat to power ratio of the CHP is a measure of the proportion of thermal and electrical energy generations in equivalent units. This factor is mainly used to apportion the total cost and environmental parameters of the CHP proportionately to the electrical energy generation part as per equation: Attribute $_{C H P}($ Electrical $)=\left(\right.$ Total Attribute CHP $\left._{P}\right) /(n+1)$.

${ }^{b}$ As per [19] with costs in US $\$$ (2010 price) assumed to be costs in $£$ (2012 price).

${ }^{c}$ At discount rate of $7 \%$ and 20 years period.

${ }^{d}$ As per [19] with cost in US $\$$ converted to $£$ (by dividing by 1.5 ).

TABLE III

OPTIMAL RESULTS

\begin{tabular}{|c|c|c|c|c|c|c|}
\hline \multirow{2}{*}{ DG Units } & \multicolumn{2}{|c|}{ Case A (Lowest DG Cost) } & \multicolumn{2}{|c|}{ Case B (Lowest Emission Factor) } & \multicolumn{2}{|c|}{ Case C (Lowest Line Losses) } \\
\hline & $\begin{array}{l}\text { Penetration Level } \\
(\%)\end{array}$ & $\begin{array}{l}\text { Total No. Se- } \\
\text { lected }\end{array}$ & $\begin{array}{l}\text { Penetration Level } \\
(\%)\end{array}$ & $\begin{array}{l}\text { Total No. Se- } \\
\text { lected }\end{array}$ & $\begin{array}{l}\text { Penetration Level } \\
(\%)\end{array}$ & $\begin{array}{l}\text { Total No. Se- } \\
\text { lected }\end{array}$ \\
\hline Diesel & 0 & 0 & 0.417 & 20 & 5.2749 & 253 \\
\hline GT & 0 & 0 & 5.0264 & 263 & 4.8162 & 252 \\
\hline CHP & 0.0133 & 1 & 3.5488 & 267 & 3.4159 & 257 \\
\hline $\mathrm{SPV}^{a}$ & 0 & 0 & 0.5666 & 255 & 0.5599 & 252 \\
\hline WT & 0 & 0 & 1.4136 & 270 & 1.3403 & 256 \\
\hline Total Penetration Level (\%) & 0.0133 & - & 10.9724 & - & 15.4072 & - \\
\hline $\begin{array}{l}\text { Average } \\
(£ / \mathrm{kWh})^{b}\end{array}$ & 0.3 & - & 0.2512 & - & 0.2356 & - \\
\hline Total DG Benefits $(£)$ & 3,203 & - & $5,794,541$ & - & $-5,272,303$ & - \\
\hline $\begin{array}{l}\text { Energy Generation from Existing } \\
\text { Generators (MWh/year) }\end{array}$ & $2,386,200$ & - & $2,095,100$ & - & $1,985,700$ & - \\
\hline
\end{tabular}

${ }^{a}$ Less numbers of SPV are selected for optimal solutions, mainly due to the fact that the SPV is constrained by its highest levelised cost of generation as well as lowest capacity factor (Table II).

${ }^{b}$ Average Cost of Electricity for base case (without any DG inclusion) $=0.3 £ / \mathrm{kWh}$.

include higher number of these technologies as evident in Table III.

Lifetime of DG technologies also affect their levelised cost calculations. Normally lifetimes of DG units are assumed to be 20 years. However, there in ambiguity regarding the lifetime of renewable DG technologies like SPV and WT. The effective lifetimes of these renewable DG technologies have been reported by various researchers to be around 30 years or even more. The longer lifetimes of renewable technologies result in lower levelised cost of energy generation making them more attractive financially compared to non-renewable DG technologies. To illustrate this, $L C O E$ of SPV and WT are calculated based on their lifetime of 30 years. Referring to Table II, the annuity factor at 30 year period and discount 
TABLE IV

RENEWABle DG ATtRIBUtes AT DifFERENT LifETIMES

\begin{tabular}{|c|c|c|c|c|c|c|}
\hline \multirow{2}{*}{ DG Units } & \multicolumn{2}{|c|}{ Case A (Lowest DG Cost) } & \multicolumn{2}{|c|}{ Case B (Lowest Emission Factor) } & \multicolumn{2}{|c|}{ Case C (Lowest Line Losses) } \\
\hline & $\begin{array}{l}\text { Penetration } \\
\text { Level }(\%) \text { at } \\
20 \text { Yrs }\end{array}$ & $\begin{array}{l}\text { Penetration Level } \\
(\%) \text { at } 30 \mathrm{Yrs}\end{array}$ & $\begin{array}{l}\text { Penetration Level } \\
(\%) \text { at } 20 \text { Yrs }\end{array}$ & $\begin{array}{l}\text { Penetration } \\
\text { Level }(\%) \text { at } \\
30 \text { Yrs }\end{array}$ & $\begin{array}{l}\text { Penetration } \\
\text { Level }(\%) \text { at } \\
20 \text { Yrs }\end{array}$ & $\begin{array}{l}\text { Penetration } \\
\text { Level }(\%) \text { at } \\
30 \text { Yrs }\end{array}$ \\
\hline SPV & 0 & 0 & 0.5666 & 0.5877 & 0.5599 & 0.5955 \\
\hline$\overline{\text { WT }}$ & 0 & 0.0052 & 1.4136 & 1.4822 & 1.3403 & 1.3560 \\
\hline $\begin{array}{l}\text { Average Cost of Electric- } \\
\text { ity }(£ / \mathrm{kWh})\end{array}$ & 0.3 & 0.3 & 0.2512 & 0.2467 & 0.2356 & 0.2306 \\
\hline
\end{tabular}

rate of $7 \%$ becomes 12.41 . With other parameters remaining the same, the LCOE of SPV and WT considering 30 years lifetimes become 0.30498 and $0.14568 £ / \mathrm{kWh}$ respectively.

Table IV lists the different penetration levels and the average cost of electricity for the three optimum cases considered earlier for two different lifetimes of the renewable DG units (SPV and WT). It shows that although for case A (lowest DG cost) where the DG units are selected in few numbers, the difference is not much significant. But for Cases B and C, consideration of the longevity of operation of the DG technologies result in higher penetration of the these technologies. With lower $L C O E$ resulting in higher penetration levels, the average cost of electricity also decreases in general. Thus DG technologies will become more attractive considering their longevity of operation.

\section{CONCLUSIONS}

The paper proposed an efficient MOEA/SPEA2 based framework for distribution generation planning. It is expected that the method will allow all players/network operators to understand the trade-off relationship of the cost functions. The economic benefits of deploying various renewables and nonrenewables DG systems can also be exploited through the proposed method. The SPEA2 approach being considered needs ascertaining and evaluating various internal parameters and system attributes that are essential for evolving the solution vectors towards the Pareto-optimal front. Specially, $L C O E$ calculation methods of DG technologies need further scrutiny. It is expected that renewable DG with longer lifetime will offer attractive options compared to the non-renewable DG if their longevity of lifetime is reflected properly in the calculation of the levelised costs over the planning horizon considered, as indicated in Table IV.

\section{REFERENCES}

[1] H. Kopka and P. W. Daly, A Guide to $\mathrm{BT}_{E} X$, 3rd ed. Harlow, England: Addison-Wesley, 1999.

[2] IEA, "Distributed Generation in Liberalised Electricity Markets," International Energy Agency, 2002.

[3] H. Mori and Y. Yamada, "An efficient multi-objective meta-heuristic method for distribution network expansion planning", IEEE Lausanne Powertech, vol. 1-5, pp. 374-379, 2007.

[4] A. Alarcon-Rodriguez, G. Ault, and S. Galloway, "Multi-objective planning of distributed energy resources: A review of the state-of-the-art,' Renewable \& Sustainable Energy Reviews, vol. 14, no. 5, pp. 1353-1366, 2010.

[5] R. D. Zimmerman, C. E. Murillo-Sanchez, and R. J. Thomas, "MATPOWER's Extensible Optimal Power Flow Architecture," Power and Energy Society General Meeting, 2009 IEEE, pp. 1-7, July 26-30 2009.
[6] E. Zitzler, M. Laumannsm, and L. Thiele, "Improving the Strength Pareto Evolutionary Algorithm," Swiss Federal Institute of Technology (ETH) Zurich, TIK-Report 103, 2001.

[7] A. D. Alarcon-Rodriguez, "A multi-objective planning framework for analysing the integration of distributed energy resources," PhD Doctoral Thesis, University of Strathclyde, Glasgow, 2009.

[8] DEFRA, "Guidelines to DEFRA's GHG Conversion Factors (Annexes updated April 2008)," [Online] available: http://www.defra.gov.uk/environment/business/envrp/pdf/ghg-cfguidelinesannexes2008.pdf, 2008.

[9] IEEE 14 Bus Test System, [Online] available: http://www.ee. washington.edu/research/pstca/pf14/pg_tca14bushtm, Accessed: 2012.

[10] BRECSU, "Small-scale combined heat \& power for buildings," UK: Building Research Energy Conservation Support Unit, Good Practice Guide 176, 1996.

[11] Melovic, D. and Strbac, F., "Statistical Model for Design of Distribution Network", IEEE Power Tech Conference, Bologna, Italy, June 2003.

[12] Y. A. Katsigiannis and P. S. Georgilakis, "A multiobjective evolutionary algorithm approach for the optimum economic and environmental performance of an off-grid power system containing renewable energy sources," Journal of Optoelectronics and Advanced Materials, vol. 10, no. 5, pp. 1233-1240, 2008.

[13] DECC, "Estimated emissions reduction from packaged CHP," Department of Energy \& Climate Change, [Online] available: http://chp.decc.gov.uk/cms/emissions-reductions/, 2011.

[14] ofgem, "FIT payment rate," [Online] available: http:// www. ofgem. gov. uk/Pages/MoreInformation.aspx?docid=30\&refer=SUSTAINABILITY/ ENVIRONMENT/FITS, Accessed: 2011.

[15] T. Ackermann, G. Andersson, and L. Soder, "Distributed generation: a definition", Electric Power Systems Research 57, no. 3, pp. 195-204, 2001.

[16] D. Westermann, S. Nicolai, and P. Bretschneider, "Energy Management for Distribution Networks with Storage Systems - A Hierarchical Approach”, IEEE Power \& Energy Society General Meeting, pp. 1-6, 2008.

[17] G. Celli, S. Mocci, F. Pilo, and M. Loddo, "Optimal integration of energy storage in distribution networks", 2009 IEEE Bucharest PowerTech, pp. $1-7,2009$

[18] T. Griffin, K. Tomsovic, D. Secrest, and A. Law, "Placement of dispersed generation systems for reduced losses", Proc. of the 33rd Annual Hawai International Conference System Sciences 2000, pp. 9, 2000.

[19] A. S. Siddiqui, R. M. Firestone, S. Ghosh, M. Stadler, J. L. Edwards, and C. Marnay, "Distributed energy resources customer adoption modeling with combined heat and power applications," Lawrence Berkeley National Laboratory, 2003.

[20] AEA, "The Impacts of Distributed Generation on the Wider UK Energy System Extension of the Project," Final Report to C.E.O.S.A., DEFRA, AEA Energy and Environmental, April 2008.

[21] ARUP, "Review of the generation costs and deployment potential of renewable electricity technologies in the UK," Study Report submitted to Department of Energy and Climate Change (DECC), Oct 2011.

[22] CumminsPower, "Generator set data sheet," [Online] available: http://www.cumminspower.com/www/common/templatehtml/technicaldo cument/Sp ecSheets/Diesel/na/d-3425.pdf, 2008, Accessed: 2012.

[23] Element Energy, "The growth potential for Microgeneration in England, Wales and Scotland", Final Appendix, [Online] available: http://webarchive.nationalarchives.gov.uk/+/http://www.berr.gov.uk/files/ file46421.pdf, Accessed: 2012. 